\title{
Characterization and Stability Evaluation of Thymoquinone Nanoemulsions Prepared by High-Pressure Homogenization
}

\author{
Zaki Tubesha, ${ }^{1,2,3}$ Zuki Abu Bakar, ${ }^{1,4}$ and Maznah Ismail ${ }^{1,2}$ \\ ${ }^{1}$ Laboratory of Molecular Biomedicine, Institute of Bioscience, Universiti Putra Malaysia, 43400 Serdang, Selangor, Malaysia \\ ${ }^{2}$ Department of Nutrition and Dietetics, Faculty of Medicine and Health Sciences, Universiti Putra Malaysia, 43400 Serdang, \\ Selangor, Malaysia \\ ${ }^{3}$ Department of Nutrition and Food Technology, Faculty of Agriculture, Hebron University, 90100 Hebron, Palestine \\ ${ }^{4}$ Department of Veterinary Preclinical Sciences, Faculty of Veterinary Medicine, University Putra Malaysia, 43400 Serdang, \\ Selangor, Malaysia
}

Correspondence should be addressed to Maznah Ismail; maznah@medic.upm.edu.my

Received 6 June 2013; Revised 25 September 2013; Accepted 25 September 2013

Academic Editor: Zhongkui Hong

Copyright (C) 2013 Zaki Tubesha et al. This is an open access article distributed under the Creative Commons Attribution License, which permits unrestricted use, distribution, and reproduction in any medium, provided the original work is properly cited.

\begin{abstract}
Despite the pharmacological properties of thymoquinone (TQ), its administration in vivo remains problematic partly due to its poor water solubility, leading to low absorptivity and bioavailability. Hence, the objective of this study is to prepare, characterize, and evaluate the stability of TQ nanoemulsion (TQNE). Conventional emulsion from TQ (TQCE) and empty nano- and conventional emulsions from Triolein (TRNE and TRCE) are also produced for comparison purposes. The oil-in-water nanoemulsions of TQ and Triolein were produced by high-pressure homogenization. Emulsions were characterized physically by droplet size, polydispersity index, zeta potential, and refractive index. The changes of these parameters in TQNE samples stored for 6 months at 4 and $25^{\circ} \mathrm{C}$ were not statistically significant $(P<0.05)$. In addition, the initial particle sizes of TQNE and TRNE were 119.6 and $119.5 \mathrm{~nm}$, respectively. Stability studies were also performed for the period of 6 months. At the end of the experiment, the percent of remaining TQ in TQNE at 4,25 , and $40^{\circ} \mathrm{C}$ was $90.6,89.1$, and $87.4 \%$ respectively. Slower degradation of TQ indicated the chemical stability of TQ in TQNE samples. These results indicated that TQNE is stable over a period of 6 months.
\end{abstract}

\section{Introduction}

Excessive production of free radical species through oxidative processes can lead to alteration of cellular functions responsible for cardiovascular diseases, neurodegenerative diseases, diabetes, cancer, joint diseases, and aging [1]. The damaging effects of free radicals are typically balanced by antioxidants acting as free radical suppressors or scavengers such as antioxidant enzymes, tocopherols, flavonoids, polyphenols, and quinones $[1,2]$. Hence, there is a great demand for natural bioactives for the maintenance of health and reducing the risk of disease [3]. Thymoquinone (Figure 1) is a liposoluble benzoquinone-based phytochemical that has been shown to have remarkable antioxidant and anticancer activities [1]. Although thymoquinone is a powerful antioxidant, its administration in vivo remains problematic partly due to its poor water solubility, leading to low absorptivity and bioavailability [4]. The design and development of new drug delivery systems with a view to enhance the efficacy of existing drugs is an ongoing process in pharmaceutical research [5]. Therefore, producing suitable formulations is very important to improve the solubility and bioavailability of such drugs. The lipid based formulation approach has attracted wide attention in order to enhance drug solubilization in the gastrointestinal tract [5-7].

Studies suggest that there is an inverse relationship between the absorption of poorly water-soluble bioactive components and their particle sizes [8]. Nanoemulsions mainly covering a size range of $20-200 \mathrm{~nm}$ are characterized by their great stability in suspension due to their very small particle size [9]. Because nanoemulsions have a remarkable small oil droplets size, it scattrer light weakly, and appear 
<smiles>CC1=CC(=O)C(C(C)C)=CC1=O</smiles>

FIGURE 1: Chemical structure of thymoquinone.

transparent which can be incorporated into optically transparent products without adversely affecting their clarity [10]. Furthermore, nanoemulsions are attractive candidates for improving drug solubility, reduce side effects of various potent drugs, and prolong the pharmacological effects in comparison to conventional formulations such as conventional emulsions [11]. Hence, the objective of this investigation is to prepare, characterize and evaluate the stability of nanoemulsion from thymoquinone (TQNE). Conventional emulsion from TQ (TQCE) and empty emulsions from Triolein (TR) are also produced for comparison purposes.

\section{Materials and Methods}

2.1. Materials. Methanol and 2-propanol (HPLC, grade) were purchased from Fisher Scientific Co., Ltd. (Ottawa, Ontario, Canada). The TQ standard, Triolein (TR), and polysorbate 80 (Tween 80) were purchased from Sigma (Sigma-Aldrich Co., St. Louis, Missouri, USA). Bidistilled water was used for emulsions preparation.

2.2. Production of Emulsions. Oil-in-water nanoemulsion from thymoquinone (TQNE) was prepared by homogenizing $5 \%$ of Triolein (containing $4.45 \%$ TQ) with 95\% aqueous phase (2\% Tween-80 and 93\% double distilled-water) using two sequential homogenization methods. The first method involved homogenizing the solutions in an Ultra-Turrax T25 (IKA, Staufen, Germany) for $3 \mathrm{~min}$ at $13000 \mathrm{rpm}$ to produce TQ conventional emulsion (TQCE). The second method involved subjecting the previously prepared emulsion to a high-pressure homogenization process using a bench top high-pressure homogenizer (Stansted Fluid Power, Ltd., Essex, UK) at a pressure of 800 bar for 5 cycles to produce the TQNE. To avoid degradation of bioactives, the nanoemulsion was cooled to less than $25^{\circ} \mathrm{C}$ using an ice bath after each homogenization cycle. The empty emulsions from Triolein (without TQ) were also developed as described before for comparison purpose.

2.3. Characterization of Emulsions. The changes in particle size, polydispersity index (PDI), and zeta potential of different emulsion samples were investigated over a period of 6 months at three different storage temperatures $\left(4 \pm 2^{\circ} \mathrm{C}\right.$, $25 \pm 2^{\circ} \mathrm{C}$, and $40 \pm 2^{\circ} \mathrm{C}$, resp.) and different time intervals $(0$, $15,30,45,90$, and 180 days). Refractive indices of emulsion samples were also evaluated at 0, 45, 90, and 180 days with the same storage temperatures mentioned before.

2.3.1. Droplet Size and Polydispersity Index Measurements. The mean particle size and polydispersity index were measured at $25^{\circ} \mathrm{C}$ by dynamic light scattering (DLS) using a Malvern Zetasizer Nano ZS (Malvern Instruments, Malvern, UK). The size of the particles was measured using disposable capillary cuvette (DTS1060) equipped with electrodes. To avoid multiple scattering effects in the measurements, samples were diluted 100-fold with double-distilled water immediately before measurement [8]. The droplet size and PDI of the investigated samples were obtained (in triplicate) by calculating the average of 13 measurements at an angle of $173^{\circ}[12,13]$.

2.3.2. Particle Surface Charge (Zeta Potential) Measurements. The zeta potential was measured by the measurement of the electrophoretic mobility using a Malvern Zetasizer Nano ZS (Malvern Instruments, Malvern, UK). Directly after measuring the particle size, $\zeta$-potential was measured using the same capillary cuvette. The refractive index was kept at 1.33 and the viscosity was kept at $0.89 \mathrm{cp}$ to mimic the values for pure water. Each sample was measured three times, and mean value and standard deviation are presented $[14,15]$.

2.3.3. Refractive Index. Refractive index of samples was determined using an Abbes type refractometer (Bellinghan and Stanley Ltd., Tunbridge Wells, UK). Each sample was measured three times, and mean value and standard deviation (SD) are presented [16].

2.3.4. Chemical Stability Studies. The loss of TQ in nanoand conventional emulsion samples (TQNE and TQCE) was investigated over a period of 6 months at 3 different storage temperatures $\left(4,25\right.$, and $\left.40^{\circ} \mathrm{C}\right)$. Therefore, quantification of TQ was performed using HPLC method according to Al-Naqeeb and Ismail [17]. An Agilent HPLC (1200 series, Germany) with C-18 reversed-phase column (Zorbax SBC18: Agilent, Muskegon, MI., USA) was used in the TQ quantifications. For sample preparation, both TQ standard and the emulsion samples were diluted and dissolved in absolute methanol to 100 and 1000 ppm, respectively, and filtered through a $0.22 \mu \mathrm{m}$ Millipore filters. Diluted samples were sonicated in an ultrasonic bath at $30^{\circ} \mathrm{C}$ for $10 \mathrm{~min}$ to ensure dissolving. The mobile phase consisting of water, methanol, and isopropanol [50:45:5(v/v/v)] with a flow rate of $1.0 \mathrm{~mL} / \mathrm{min}$ at $254 \mathrm{~nm}$ was used in the study. The TQ standard solution $(3.125,6.25,12.5,25,50$, and $100 \mu \mathrm{g}$ $\mathrm{TQ} / \mathrm{mL}$ methanol) was used to prepare the standard curve. Afterwards, $20 \mu \mathrm{L}$ of the diluted emulsions and the TQ standard solutions were injected into the HPLC column. The area of the TQ peak was reported to a calibration curve to determine the concentration of TQ. Samples were analyzed in duplicate; mean and standard deviation were calculated. The TQ content that was analyzed immediately after emulsion preparation was used as controls (100\% TQ). The amount 
of remaining TQ (undecomposed) at each time interval was calculated.

\section{Statistical Analysis}

All experiments were conducted in triplicate or duplicate. The data were recorded as mean \pm standard deviation and analyzed by SPSS (version 19, SPSS Inc, Chicago, IL). Data were analyzed using one-way ANOVA, followed by least significant difference (LSD). A value of $P<0.05$ was deemed to be statistically significant.

\section{Results and Discussion}

4.1. Droplet Size Measurements. The information on droplet size and polydispersity index is particularly important for understanding the behavior of emulsions. In addition, particle size and composition of the emulsions greatly influence the bioacceptability of the delivery systems [18]. Table 1 shows the particle size of different emulsion samples during the 6month stability study period and at different temperatures (4, 25 , and $40^{\circ} \mathrm{C}$ ). The results did not show any phase separation or any sign of instability of all nanoemulsion samples. The initial particle sizes of TQNE (Figure 2(a)) and TRNE were 119.6 and $119.5 \mathrm{~nm}$, respectively. In addition, TQNE and TRNE showed particle size ranges of 116.7-122.7 and 117.2$120.8 \mathrm{~nm}$, respectively. Moreover, their mean particle sizes were not significantly different during the study period at all the storage temperatures. On the other hand TQCE and TRCE showed particle size ranges of 489.2-680.2 and 458.3$629.0 \mathrm{~nm}$, respectively. After 6 months of storage at different temperatures $\left(4,25\right.$, and $\left.40^{\circ} \mathrm{C}\right)$, the changes in particle size of TQCE samples were not significant in samples stored at 4 and $40^{\circ} \mathrm{C}$, while at $25^{\circ} \mathrm{C}$ the psarticle size significantly increased compares to day 0 . However, changes in particle size of TRCE were not significant at $4^{\circ} \mathrm{C}$, while it was significantly increased in samples stored at 25 and $40 \circ \mathrm{C}$ if compared to day 0 .

A very small particle size $(200-400 \mathrm{~nm})$ even smaller than the size of the smallest blood capillaries allows the nanoemulsions to be injected intravenously with minimal chances of capillary blockage during transport of the droplets. This provides $100 \%$ bioavailability and simultaneously avoids the use of toxic surfactants or cosolvents to dissolve the drug [19]. In addition, nanoemulsions are usually highly stable to gravitational separation because the relatively small droplet size means that Brownian motion effects dominate the gravitational forces. Therefore, nanoemulsions tend to have better stability against droplet aggregation than conventional emulsions [20]. However, emulsions may become unstable through a number of different instability mechanisms (e.g., flocculation, coalescence, Ostwald ripening, and gravitational separation), which depend on storage conditions such as $\mathrm{pH}$, ionic strength, and temperature [21].

4.2. Polydispersity Index Measurements. Table 2 shows the PDI of different emulsion samples during the 6-month stability study period at different temperatures $\left(4,25\right.$, and $\left.40^{\circ} \mathrm{C}\right)$ and different time intervals $(0,15,30,45,90$, and 180 days).

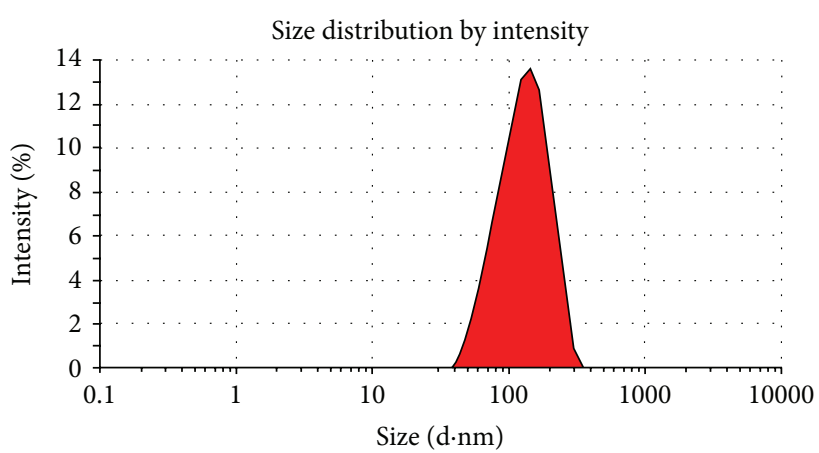

(a)

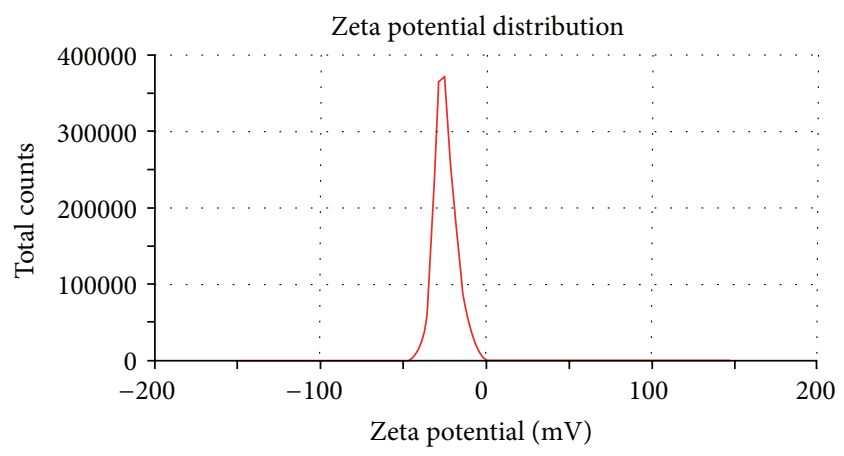

(b)

FIgUre 2: Particle size distribution (a) and zeta potential (b) of TQNE at day 0 .

TQNE and TRNE showed PDI range of $0.175-0.207$ and $0.158-0.211$ respectively. In addition, PDI of TQCE and TRCE was in the range of $0.488-0.677$ and $0.423-0.616$, respectively. The PDI reflects the uniformity of particle diameter and can be used to depict the size distribution of emulsion particles [22]. At the end of the study, the PDI of TQNE and TRNE samples had a value less than 0.2 , this indecates a very narrow size distributions of the system, which may reflect the overall stability of these samples. Polydispersity values near 1.0 are indicative of a polydisperse system [23].

4.3. Particle Surface Charge of Emulsions. Emulsifiers not only act as a mechanical barrier but also act through formation of surface charges zeta potential, which can produce repulsive electrical forces among approaching oil droplets and this hinders coalescence [24]. Zeta potential is a technique used to measure the particle surface charge properties and predict the physical stability of many drug delivery systems [25]. High absolute zeta potential values (above $30 \mathrm{mV}$ ) should preferably be achieved in most nanoemulsions prepared in order to ensure the creation of a high-energy barrier against coalescence of the dispersed droplets [22]. Figure 3 shows the zeta potential of loaded and empty emulsions during the 6-month stability study period and at different temperatures $\left(4,25\right.$, and $\left.40^{\circ} \mathrm{C}\right)$. The initial zeta potential of TQNE (Figure 2(b)) and TRNE was $-30.5 \pm 0.85$ and $-28.8 \pm$ 0.88 , respectively. After a six-month storage of TQNE, the changes in zeta potential were not significant for samples 
TABLE 1: Particle size (nm) of different emulsion samples during storage for 6 months at different temperatures.

\begin{tabular}{|c|c|c|c|c|c|c|}
\hline & $4^{\circ} \mathrm{C}$ & $25^{\circ} \mathrm{C}$ & $40^{\circ} \mathrm{C}$ & $4^{\circ} \mathrm{C}$ & $25^{\circ} \mathrm{C}$ & $40^{\circ} \mathrm{C}$ \\
\hline & & TQNE & & & TRNE & \\
\hline D0 & $119.6 \pm 0.88$ & $119.6 \pm 0.88$ & $119.6 \pm 0.88$ & $119.5 \pm 0.52$ & $119.5 \pm 0.52$ & $119.5 \pm 0.52$ \\
\hline D15 & $120.3 \pm 0.64$ & $119.2 \pm 0.70$ & $121.3 \pm 0.20$ & $119.7 \pm 0.15$ & $119.3 \pm 0.25$ & $119.5 \pm 0.45$ \\
\hline D30 & $121.1 \pm 0.40$ & $119.0 \pm 0.80$ & $122.7 \pm 3.0$ & $119.7 \pm 0.51$ & $118.4 \pm 0.50$ & $120.8 \pm 0.26$ \\
\hline D45 & $118.0 \pm 0.52$ & $116.7 \pm 0.72$ & $117.7 \pm 0.80$ & $117.2 \pm 0.50$ & $117.2 \pm 0.68$ & $117.9 \pm 0.41$ \\
\hline D90 & $119.3 \pm 0.70$ & $118.3 \pm 0.60$ & $117.6 \pm 0.70$ & $117.2 \pm 0.36$ & $117.9 \pm 0.70$ & $119.6 \pm 0.36$ \\
\hline \multirow[t]{2}{*}{ D180 } & $118.9 \pm 0.15$ & $119.1 \pm 0.40$ & $119.4 \pm 0.75$ & $117.9 \pm 0.72$ & $118.1 \pm 0.95$ & $120.6 \pm 1.1$ \\
\hline & & TQCE & & & TRCE & \\
\hline D0 & $571.8 \pm 5.1$ & $571.8 \pm 5.1$ & $571.8 \pm 5.1$ & $511.8 \pm 2.5$ & $511.8 \pm 2.5$ & $511.8 \pm 2.5$ \\
\hline D15 & $519.8 \pm 12.6$ & $494.7 \pm 2.8^{*}$ & $536.1 \pm 0.05$ & $500.6 \pm 26.0$ & $548.8 \pm 4.8$ & $545.6 \pm 5.0$ \\
\hline D30 & $500.8 \pm 10.2^{*}$ & $601.0 \pm 10.2$ & $680.2 \pm 31.5^{*}$ & $544.2 \pm 18.3^{*}$ & $550.8 \pm 2.8$ & $511.6 \pm 1.2$ \\
\hline D45 & $506.1 \pm 3.03^{*}$ & $597.4 \pm 10.9$ & $538.3 \pm 38.6$ & $565.0 \pm 2.0^{*}$ & $560.9 \pm 17.4$ & $518.2 \pm 36.0$ \\
\hline D90 & $513.7 \pm 5.0^{*}$ & $489.2 \pm 16.2^{*}$ & $522.3 \pm 3.5$ & $458.3 \pm 13.9^{*}$ & $567.4 \pm 9.6$ & $545.8 \pm 25.3$ \\
\hline D180 & $522.6 \pm 61.1$ & $498.3 \pm 43.8^{*}$ & $607.3 \pm 45.1$ & $486.4 \pm 25.8$ & $648.6 \pm 109^{*}$ & $629.0 \pm 25.8^{*}$ \\
\hline
\end{tabular}

Values are means of three replicates. Means in the same column of each emulsion with asterisks $\left(^{*}\right)$ denote significance compared to day $0(P<0.05)$. D: day.

TABLE 2: Polydispersity indices of different emulsion samples during storage for 6 months at different temperatures.

\begin{tabular}{|c|c|c|c|c|c|c|}
\hline & $4^{\circ} \mathrm{C}$ & $25^{\circ} \mathrm{C}$ & $40^{\circ} \mathrm{C}$ & $4^{\circ} \mathrm{C}$ & $25^{\circ} \mathrm{C}$ & $40^{\circ} \mathrm{C}$ \\
\hline & & TQNE & & & TRNE & \\
\hline D0 & $0.194 \pm 0.011$ & $0.194 \pm 0.011$ & $0.194 \pm 0.011$ & $0.191 \pm 0.011$ & $0.191 \pm 0.011$ & $0.191 \pm 0.011$ \\
\hline D15 & $0.194 \pm 0.015$ & $0.201 \pm 0.007$ & $0.207 \pm 0.004$ & $0.194 \pm 0.008$ & $0.201 \pm 0.005$ & $0.168 \pm 0.011^{*}$ \\
\hline D30 & $0.184 \pm 0.004$ & $0.175 \pm 0.002^{*}$ & $0.190 \pm 0.010$ & $0.198 \pm 0.011$ & $0.189 \pm 0.009$ & $0.211 \pm 0.010$ \\
\hline D45 & $0.182 \pm 0.004$ & $0.184 \pm 0.011$ & $0.184 \pm 0.007$ & $0.180 \pm 0.001$ & $0.181 \pm 0.009$ & $0.199 \pm 0.005$ \\
\hline D90 & $0.193 \pm 0.017$ & $0.189 \pm 0.007$ & $0.193 \pm 0.004$ & $0.186 \pm 0.007$ & $0.203 \pm 0.008$ & $0.160 \pm 0.007^{*}$ \\
\hline \multirow[t]{2}{*}{ D180 } & $0.181 \pm 0.015$ & $0.192 \pm 0.006$ & $0.176 \pm 0.003^{*}$ & $0.195 \pm 0.006$ & $0.189 \pm 0.011$ & $0.158 \pm 0.012^{*}$ \\
\hline & & TQCE & & & TRCE & \\
\hline D0 & $0.570 \pm 0.001$ & $0.570 \pm 0.001$ & $0.570 \pm 0.001$ & $0.542 \pm 0.064$ & $0.542 \pm 0.064$ & $0.542 \pm 0.064$ \\
\hline D15 & $0.548 \pm 0.041$ & $0.570 \pm 0.065$ & $0.527 \pm 0.001$ & $0.508 \pm 0.023$ & $0.555 \pm 0.006$ & $0.528 \pm 0.030$ \\
\hline D30 & $0.488 \pm 0.027^{*}$ & $0.612 \pm 0.088$ & $0.677 \pm 0.035^{*}$ & $0.568 \pm 0.032$ & $0.424 \pm 0.032^{*}$ & $0.479 \pm 0.048$ \\
\hline D45 & $0.504 \pm 0.007^{*}$ & $0.599 \pm 0.026$ & $0.545 \pm 0.038$ & $0.461 \pm 0.019^{*}$ & $0.553 \pm 0.026$ & $0.526 \pm 0.079$ \\
\hline D90 & $0.515 \pm 0.023^{*}$ & $0.520 \pm 0.050$ & $0.527 \pm 0.014$ & $0.462 \pm 0.013^{*}$ & $0.443 \pm 0.034^{*}$ & $0.423 \pm 0.027^{*}$ \\
\hline D180 & $0.554 \pm 0.006$ & $0.527 \pm 0.013$ & $0.584 \pm 0.043$ & $0.490 \pm 0.026$ & $0.616 \pm 0.050$ & $0.606 \pm 0.035$ \\
\hline
\end{tabular}

Values are means of three replicates. Means in the same column of each emulsion with asterisks $\left(^{*}\right)$ denote significance compared to day $0(P<0.05)$. D: day.

stored at 4 and $25^{\circ} \mathrm{C}$, while it was significantly increased for samples at $40^{\circ} \mathrm{C}$. However, TRNE stored at $25^{\circ} \mathrm{C}$ showed a significant increase $(-32.3 \pm 0.436 \mathrm{mV})$ compared to the initial values $(-28.8 \pm 0.88)$. On the other hand, TRNE stored at $40^{\circ} \mathrm{C}$ showed a significant decrease $(-16.5 \pm 0.37 \mathrm{mV})$. After keeping TQNE samples for 6 months at different storage temperatures, they were within the recommended range which was around $-30 \mathrm{mV}$.

4.4. Refractive Index. Refractive index (RI) being an optical property is used to characterize the isotropic nature of the emulsions [26]. Figures 4 and 5 show the RI of TQ and TR emulsion samples, respectively, during the 6-month stability study period at different temperatures $\left(4,25\right.$, and $\left.40^{\circ} \mathrm{C}\right)$ and different time intervals $(0,45,90$, and 180 days). TQNE

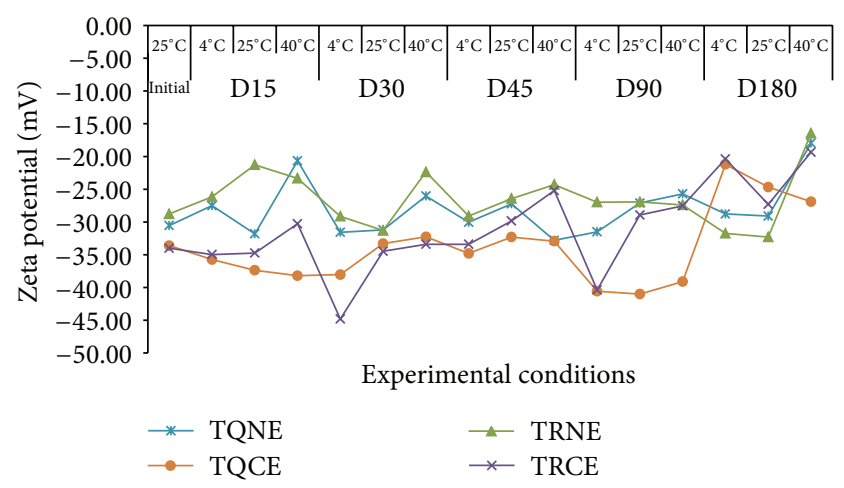

Figure 3: Mean zeta potential of different emulsion samples during storage for 6 months at different temperatures. Values are means of three replicates. 


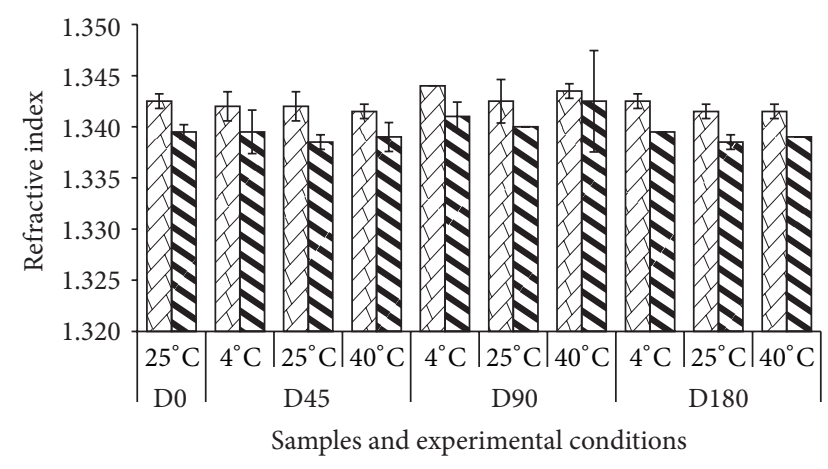

- TQCE

$\square$ TQNE

FIGURE 4: Refractive index of TQ emulsion samples during storage for 6 months at different temperatures. Values are means of three replicate determinations. For each emulsion, there was no significant difference $(P \geq 0.05)$ compared to day $0 . \mathrm{D}=$ day.

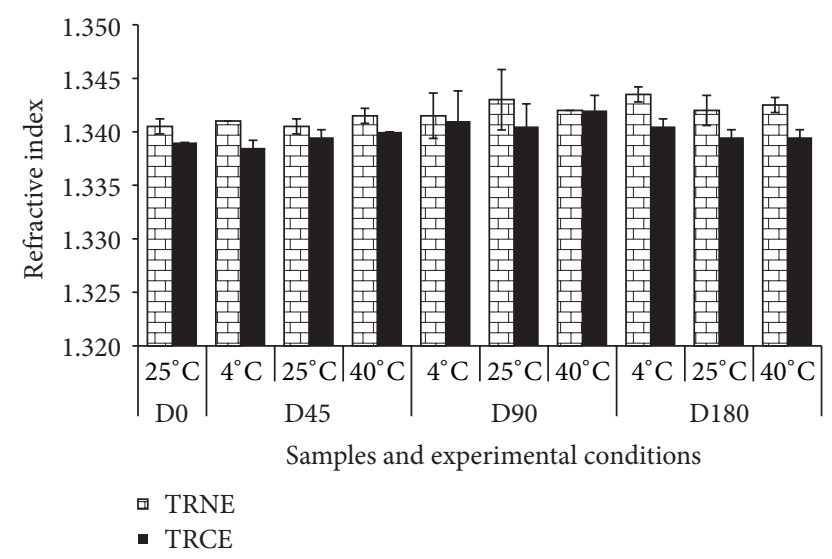

FIGURE 5: Refractive index of TR emulsion samples during storage for 6 months at different temperatures. Values are means of three replicate determinations. For each emulsion, there was no significant difference $(P \geq 0.05)$ compared to day 0 . $\mathrm{D}=$ day.

and TRNE showed RI range of 1.342-1.344 and 1.341-1.344, respectively. In addition, RI of TQCE and TRCE was in the range of $1.339-1.343$ and $1.339-1.342$, respectively. No significant difference $(P>0.05)$ was observed in the refractive indices of all emulsion samples during the study period. In all samples, the refractive index was closer to $1.342 \pm 0.004$. Similarity of the refractive index value is a sign of the uniform nanoemulsion structure. This led to the conclusion that our TQNE was not only thermodynamically stable but also isotropic in nature. A conclusion can be made that the TQNE samples were stable for up to 6 months regardless of the storage temperature.

4.5. Chemical Stability Studies. Stability of drug product is one of the problems associated with the development of nanoemulsions [27]. Chemical stability studies at temperatures 4,25 , and $40^{\circ} \mathrm{C}$ at the time period of 3 and 6 months are shown in Figure 6. The percent of remaining TQ in TQNE

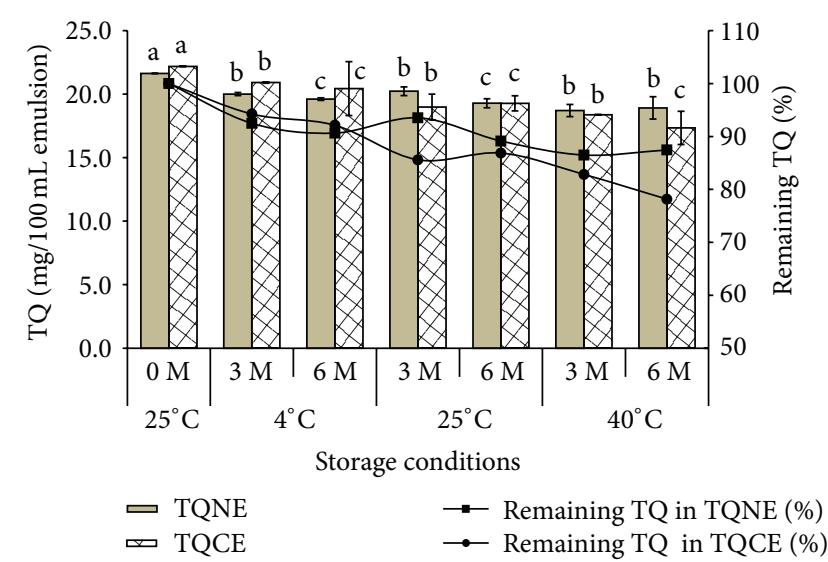

FIGURE 6: Stability profile of TQ emulsions during storage of 6 months at different temperatures. Values are means of two replicate determinations. Means not sharing a common letter are significantly different $(P<0.05)$ compared to production day $(0 \mathrm{M})$. M: month.

at 4,25 , and $40^{\circ} \mathrm{C}$ was $90.64,89.15$, and $87.45 \%$, respectively. Regardless of the significant decrease $(P<0.05)$ in TQ content in emulsion samples during the stability study period and at all storage temperatures, a good chemical stability was observed in TQNE samples stored at 4 and $25^{\circ} \mathrm{C}$; that is, the percentage of remaining TQ was approximately $90 \%$. Based on these results, it could be concluded that the best storage temperatures for the prepared emulsions were 4 and $25^{\circ} \mathrm{C}$. This degradation could be due to microbial contamination, oxidation, and photodegradation during analysis or storage period. Therefore, precautions should be taken to avoid or minimize the above reasons.

\section{Conclusion}

In conclusion, the droplet size, polydispersity index, zeta potential, and RI of TQNE were not significantly changed during 6 months of storage at 4 and $25^{\circ} \mathrm{C}$. Therefore, it was concluded that the prepared TQNE was physically stable. In addition, the degradation of TQ in TQNE after 6 months of storage at 4 and $25^{\circ} \mathrm{C}$ was lower compared to samples stored at $40^{\circ} \mathrm{C}$ which indicated the chemical stability of TQNE samples. Hence, this nanoemulsion-based delivery system can be efficiently used in the encapsulation of TQ bioactive which is stable over a period of 6 months.

\section{Conflict of Interests}

The authors have no conflict of interests with the content of this paper.

\section{Acknowledgments}

This study was supported in part by the Research University Grant Scheme, the Universiti Putra Malaysia, and the Nutrigenomic Programme. The first author gratefully acknowledges the Islamic Development bank (IDB) (Jeddah, Saudi Arabia) for a scholarship provided for the Ph.D. 


\section{References}

[1] G. M. Ganea, S. O. Fakayode, J. N. Losso, C. F. van Nostrum, C. M. Sabliov, and I. M. Warner, "Delivery of phytochemical thymoquinone using molecular micelle modified poly $(\mathrm{D}, \mathrm{L}$ lactide-co-glycolide) (PLGA) nanoparticles," Nanotechnology, vol. 21, no. 28, Article ID 285104, 2010.

[2] O. Sorg, "Oxidative stress: a theoretical model or a biological reality?” Comptes Rendus Biologies, vol. 327, no. 7, pp. 649-662, 2004.

[3] M. A. Augustin, M. Y. Abeywardena, G. Patten et al., "Effects of microencapsulation on the gastrointestinal transit and tissue distribution of a bioactive mixture of fish oil, tributyrin and resveratrol," Journal of Functional Foods, vol. 3, no. 1, pp. 25-37, 2011.

[4] F. Odeh, S. I. Ismail, R. Abu-Dahab, I. S. Mahmoud, and A. Al Bawab, "Thymoquinone in liposomes: a study of loading efficiency and biological activity towards breast cancer," Drug Delivery, vol. 19, no. 8, pp. 371-377, 2012.

[5] S. Debnath, Satayanarayana, and G. V. Kumar, "Nanoemulsiona method to improve the solubility of lipophilic drugs," Pharmanest, vol. 2, no. 2-3, pp. 72-83, 2011.

[6] G. L. Amidon, H. Lennernas, V. P. Shah, and J. R. Crison, "A theoretical basis for a biopharmaceutic drug classification: the correlation of in vitro drug product dissolution and in vivo bioavailability," Pharmaceutical Research, vol. 12, no. 3, pp. 413420, 1995.

[7] K. R. Jadhav, M. N. Gambhire, I. M. Shaikh, V. J. Kadam, and S. S. Pisal, "Nasal drug delivery system-factors affecting and applications," Current Drug Therapy, vol. 2, no. 1, pp. 27-38, 2007.

[8] Y. Li, J. Zheng, H. Xiao, and D. J. McClements, "Nanoemulsionbased delivery systems for poorly water-soluble bioactive compounds: influence of formulation parameters on polymethoxyflavone crystallization," Food Hydrocolloids, vol. 27, no. 2, pp. 517-528, 2012.

[9] N. Anton, J. P. Benoit, and P. Saulnier, "Design and production of nanoparticles formulated from nano-emulsion templates-a review," Journal of Controlled Release, vol. 128, no. 3, pp. 185-199, 2008.

[10] T. G. Mason, J. N. Wilking, K. Meleson, C. B. Chang, and S. M. Graves, "Nanoemulsions: formation, structure, and physical properties," Journal of Physics, vol. 18, no. 41, pp. R635-R666, 2006.

[11] M. P. Youenang Piemi, D. Korner, S. Benita, and J. P. Marty, "Positively and negatively charged submicron emulsions for enhanced topical delivery of antifungal drugs," Journal of Controlled Release, vol. 58, no. 2, pp. 177-187, 1999.

[12] A. Kovacevic, S. Savic, G. Vuleta, R. H. Müller, and C. M. Keck, "Polyhydroxy surfactants for the formulation of lipid nanoparticles (SLN and NLC): effects on size, physical stability and particle matrix structure," International Journal of Pharmaceutics, vol. 406, no. 1-2, pp. 163-172, 2011.

[13] M. Morille, T. Montier, P. Legras et al., "Long-circulating DNA lipid nanocapsules as new vector for passive tumor targeting," Biomaterials, vol. 31, no. 2, pp. 321-329, 2010.

[14] T. K. Vyas, A. Shahiwala, and M. M. Amiji, "Improved oral bioavailability and brain transport of Saquinavir upon administration in novel nanoemulsion formulations," International Journal of Pharmaceutics, vol. 347, no. 1-2, pp. 93-101, 2008.

[15] A. Ramadan, F. Lagarce, A. Tessier-Marteau et al., "Oral fondaparinux: use of lipid nanocapsules as nanocarriers and in vivo pharmacokinetic study," International Journal of Nanomedicine, vol. 6, pp. 2941-2951, 2011.

[16] S. Baboota, F. Shakeel, A. Ahuja, J. Ali, and S. Shafiq, "Design, development and evaluation of novel nanoemulsion formulations for transdermal potential of celecoxib," Acta Pharmaceutica, vol. 57, no. 3, pp. 315-332, 2007.

[17] G. Al-Naqeeb and M. Ismail, "Regulation of apolipoprotein A-1 and apolipoprotein $\mathrm{B} 100$ genes by thymoquinone rich fraction and thymoquinone in HEPG2 cells," Journal of Food Lipids, vol. 16, no. 2, pp. 245-258, 2009.

[18] V. Bali, M. Ali, and J. Ali, "Study of surfactant combinations and development of a novel nanoemulsion for minimising variations in bioavailability of ezetimibe," Colloids and Surfaces B, vol. 76, no. 2, pp. 410-420, 2010.

[19] S. Bansal, M. Bansal, and R. Kumria, "Nanocrystals: current strategies and trends," International Journal of Research in Pharmaceutical and Biomedical Sciences, vol. 3, no. 1, pp. 406419, 2012.

[20] D. J. McClements and Y. Li, "Structured emulsion-based delivery systems: controlling the digestion and release of lipophilic food components," Advances in Colloid and Interface Science, vol. 159, no. 2, pp. 213-228, 2010.

[21] D. J. McClements, Food Emulsions: Principles, Practice, and Techniques, CRC Press, 2nd edition, 2004.

[22] Y. Zhao, C. Wang, A. H. L. Chow et al., "Self-nanoemulsifying drug delivery system (SNEDDS) for oral delivery of Zedoary essential oil: formulation and bioavailability studies," International Journal of Pharmaceutics, vol. 383, no. 1-2, pp. 170-177, 2010.

[23] S. M. Jafari, E. Assadpoor, Y. He, and B. Bhandari, "Recoalescence of emulsion droplets during high-energy emulsification," Food Hydrocolloids, vol. 22, no. 7, pp. 1191-1202, 2008.

[24] P. K. Gupta, P. Kt, K. Ajay, S. Pallavi, and G. Sanjiv, "Pharmaceutical nanotechnology novel nanoemulsion-high energy emulsification preparation, evaluation and application," The Pharma Research, vol. 3, pp. 117-138, 2010.

[25] H. D. Silva, M. Â. Cerqueira, and A. A. Vicente, "Nanoemulsions for food applications: development and characterization," Food and Bioprocess Technology, vol. 5, no. 3, pp. 854-867, 2012.

[26] R. Parveen, S. Baboota, J. Ali, A. Ahuja, S. S. Vasudev, and S. Ahmad, "Oil based nanocarrier for improved oral delivery of Silymarin: in vitro and in vivo studies," International Journal of Pharmaceutics, vol. 413, no. 1-2, pp. 245-253, 2011.

[27] C. Lovelyn and A. A. Attama, "Current state of nanoemulsions in drug delivery," Journal of Biomaterials and Nanobiotechnology, vol. 2, no. 5, pp. 626-639, 2011. 

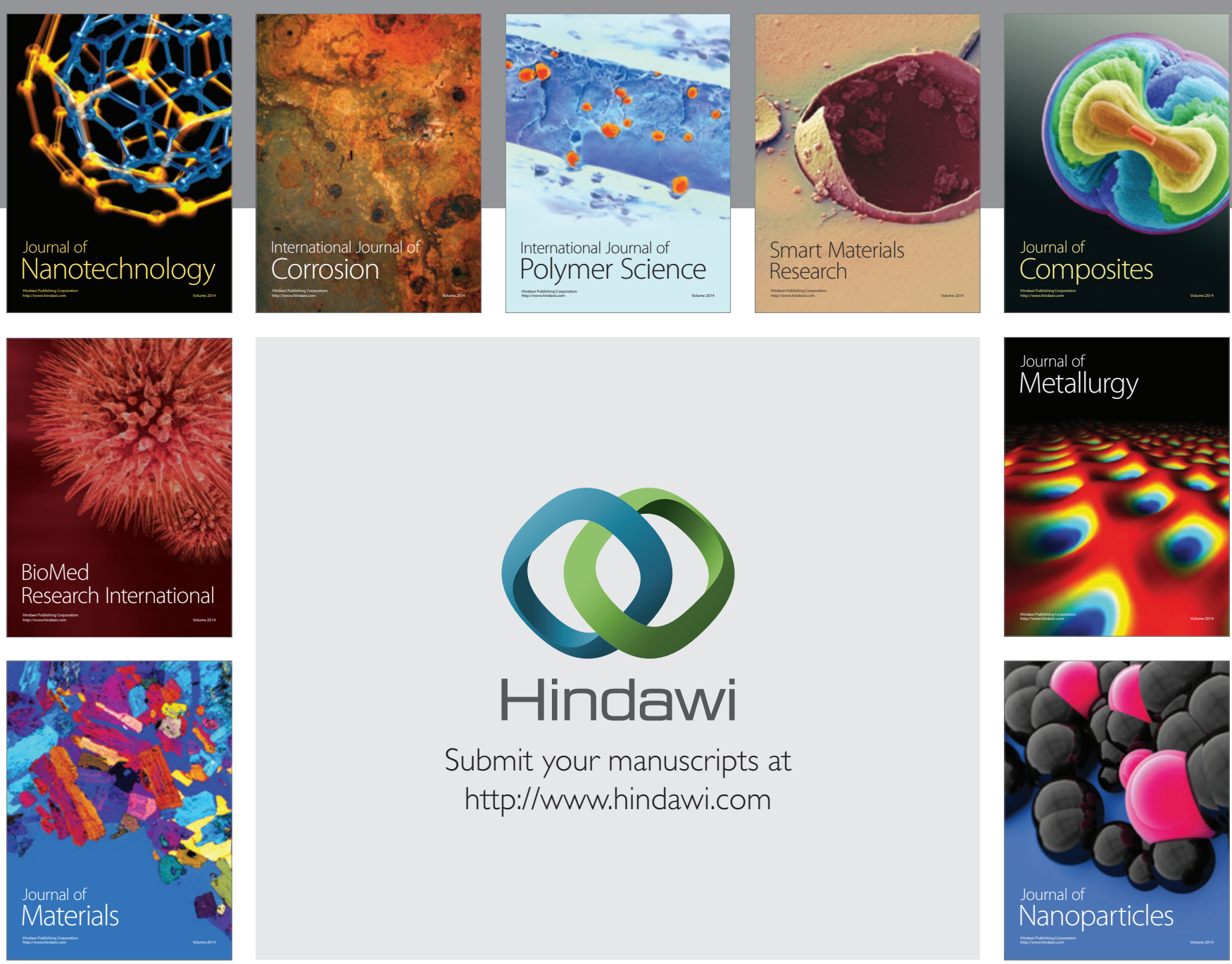

Submit your manuscripts at http://www.hindawi.com
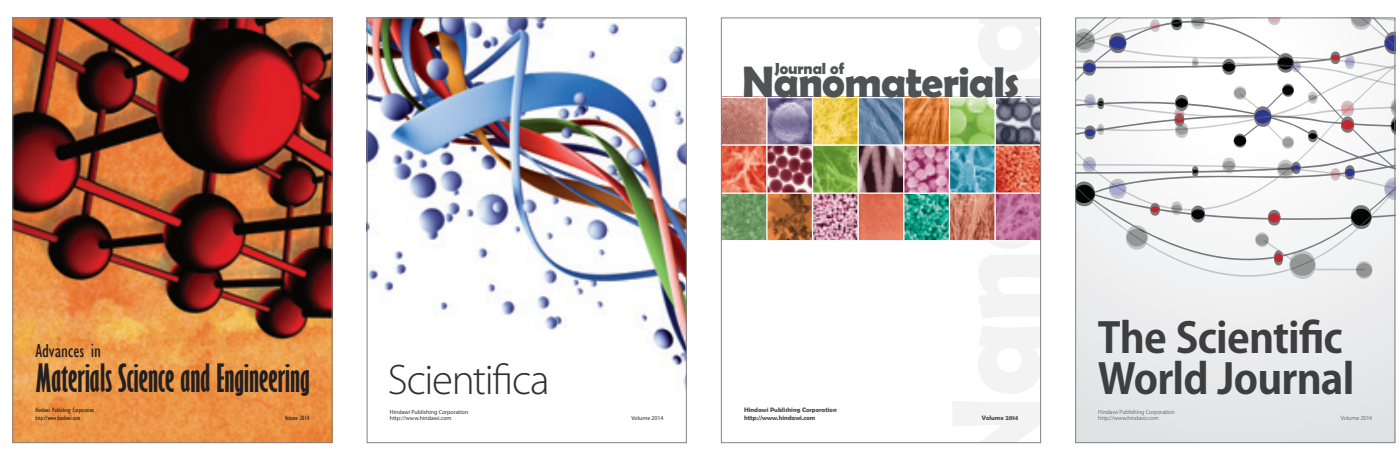

\section{The Scientific World Journal}
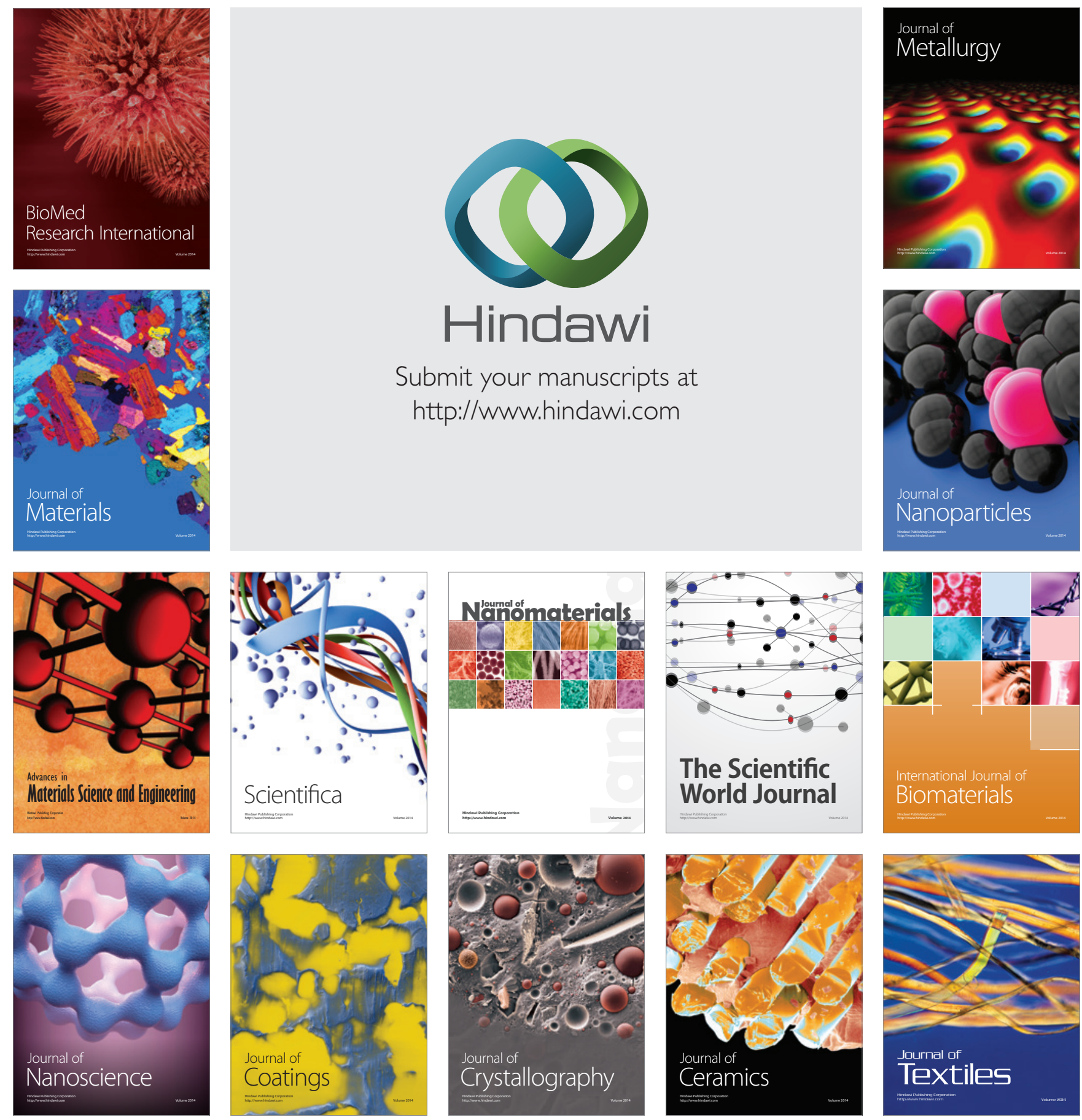